Educational Research for Social Change (ERSC)

Volume 9 No. 2 September 2020

pp. 81-100

ersc.nmmu.ac.za

ISSN: 2221-4070

\title{
Considering Craft- and Arts-Based Practitioner Inquiry Activities as a Prompt for Transforming Practice ${ }^{1}$
}

\author{
Margie Childs \\ Faculty of Education \\ Nelson Mandela University \\ Margie.childs@mandela.ac.za \\ Tobeka Mapasa \\ Faculty of Education \\ Nelson Mandela University \\ Tobeka.mapasa@mandela.ac.za \\ Marina Ward \\ Faculty Librarian: Education \\ Nelson Mandela University \\ Marina.ward@mandela.ac.za
}

\begin{abstract}
Craft- and arts-based procedures, as examples of aesthetic communication, have the potential to inspire new ways of being and doing in the context of student support activities in higher education environments. In this article, we share our experiences of using craftwork and arts-infused activities to examine our practice. In our research undertaking, we collaborated creatively in order to scrutinise and question our taken-for-granted and usual student support practices. The purpose of our inquiry was to engage with specific craft- and arts-based procedures in order to discover how transformation of practice, prompted by creative activism, could be realised. To achieve this, we developed an innovative, Crafting Connections, procedure. This hands-on technique adds to the creative repertoire available to scholars and practitioners. Material sense making employing this craftwork process and artsbased activities facilitated the exploration of student support practices. Using visual activism and a transformative activist stance as theoretical perspectives, images, crafted artefacts, and collage work were scrutinised. This positioned us to make an argument for the coalescing of understanding and prompting of transformed practice informed by creative action and insight. Through craft- and arts-based practitioner inquiry activities, we gained insights regarding ways of creating a transformative learning space for students and staff to grow towards their goals and realise their intentions in a mutually beneficial manner. Our reflections further revealed that it is essential for staff to balance nurturing with respect for agency as a key action in the student support process.
\end{abstract}

\footnotetext{
1 Ethical clearance number: H19-EDU-ERE-006
} 


\section{Keywords: crafting connections, arts-based, practitioner inquiry, transformation, practice}

\section{Copyright: (c) 2020 Childs, Mapasa \& Ward}

This is an open access article distributed under the terms of the Creative Commons Attribution NonCommercial License, which permits unrestricted non-commercial use, distribution, and reproduction in any medium, provided the original author and source are credited.

Please reference as: Childs, M., Mapasa, T. and Ward, M. (2020). Considering Craft- and ArtsBased Practitioner Inquiry Activities as a Prompt for Transforming Practice. Educational Research for Social Change, 9(2), 81-100. http://dx.doi.org/10.17159/2221-4070/2020/v9i2a6

\section{Introduction}

This paper presents a reflection on a collaborative visual conversation undertaken at a South African university. We surface the craft- and arts-based procedures used in the study and consider how transformation of practice, prompted by creative activism, can be realised. Rethinking and repositioning are stimulated by creative activism. Aesthetic messages, as a form of creative activism, have the potential to communicate with an audience beyond the usual and mundane and, potentially, bring about change (Morrow, 2007). In this text, we argue that craft- and arts-based procedures, as examples of aesthetic communication, have the potential to inspire new ways of being and doing in the context of student support activities in higher education environments.

Niedderer and Townsend (2014) claimed that using craft- and arts-based activities holds significant promise for promoting material sense making and for surfacing profound understandings of practice. Tactile knowing or "thinking through one's hands" (Groth et al., 2013, p. 1) is an embodied way of fathoming that can be used to come to creative understanding. Inspired action and improvement of practice, sometimes in unexpected ways, is possible (Rolling, 2010; Weber, 2014). Rolling reminded us that arts-based inquiry "informs by eroding predeterminations, un-naming categories, and swamping the pretense of objectivity" (2010, p. 108). When creative work takes place collaboratively, new understandings of selves and situations are possible (Masinga et al., 2016). Colleagues who take on the role of critical friends are able to offer novel viewpoints, assistance, and critique (Samaras, 2010). A creatively orientated examination of practice seemed to be a useful way to look with new eyes at student support initiatives and associated understandings of staff. In the next sections, we provide a context to our work then we outline our methodology and engagement with emerging insights. We coalesce our meaning making using a collage process.

\section{Background}

We had collaborated for many years to integrate the learning of academic and information literacies in a major module of our first-year Bachelor of Education curriculum. Our team comprised an education specialist, an academic literacies practitioner, and a teaching, learning, and research support librarian. We referred to ourselves as the Open the Book of Learning (OBL) team because our practices were intended to help first-year students open and start turning the pages of the "book" of university learning. A curriculum revision process had resulted in the phasing out of the module where our collaboration started. The cusp of phasing out one module and ushering in a new module seemed an ideal opportunity for introspection and reflection on our practice.

After the final delivery of the old module, we set up a display of documents, pictures, and artefacts linked to the module and our joint efforts to support students. The display was framed using the See, Think, Wonder (STW) visual-thinking process (Ritchhart \& Perkins, 2008; Tishman \& Palmer, 2005). Staff members were invited to view the display and engage with us as a team. Viewers could peer 
through a large window and watch as the display took shape (Image 1). Later, critical friends visited the display room, considered what they saw, and asked questions to prompt our thinking and wondering.

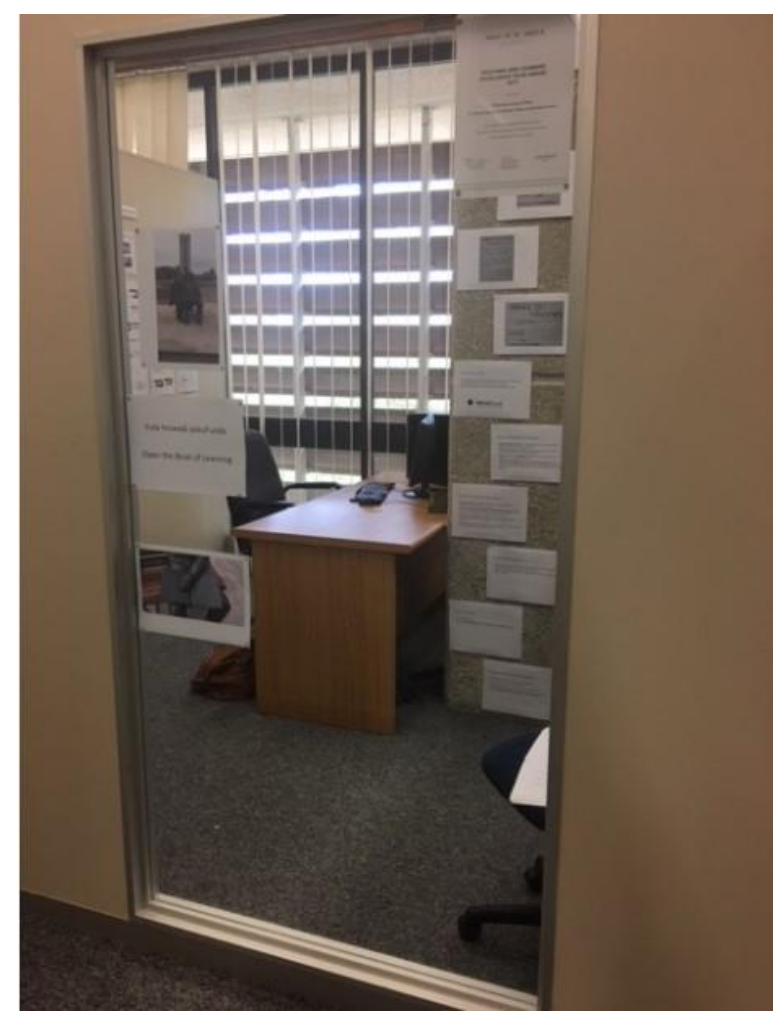

Image 1: Explore the Display: See, Think, and Wonder

Guided by the insights and critique of colleagues from the faculty and library as critical friends, we continued to deliberate, think, and write about our practice (details about recruitment of these colleagues are given in the methodology section). In order to deepen reflection, it was important to make the familiar strange (Mannay, 2010). We elicited evocative photographs to continue the artsbased interrogation of our practice because we wanted to look anew at our usual student support roles. Thereafter, critical friends were again invited into the process in order to extend learning and understanding (Berry \& Russell, 2014). They had the opportunity to think with their hands and use an innovative tactile process, Crafting Connections, to communicate insights about promoting student success.

The various creative processes enabled us (critical friends and OBL team members) to enter a visual conversation about student support. A gallery walk and viewing of the crafted constructions of critical friends was used as a means of speaking back to the insights of colleagues (Mitchell et al., 2017). In order to interpret and sharpen understandings of the messages contained in the craftwork, as the OBL team we jointly pieced together a collage (Butler-Kisber \& Poldma, 2010). This served as a powerful visual tool that made our ideas explicit. It was a way to make new insights possible for both the researchers and the research audience. The use of collage as a group, rather than an individual, process provided important communication, insight building, and meaning making for us as a team (Williams, 2002). Our work intentionally blurs the boundaries between craft and art and searches out collective ways to make sense of practice. 
At times, art and craft are considered integral parts of a particular practice and, in other instances, craft and art are held separate and valued differently. Eisner (1984) gifted us with a seminal text, The Art and Craft of Teaching. More recently, we have been offered The Art and Craft of Case Writing (Naumes \& Naumes, 2014), and even policy analysis has an art and craft aspect (Wildavsky, 2017). However, some practitioners advocate a clear distinction between art and craft. Thus, McLennan (2010) made a strong case for visual art in early childhood curricula, and indicated that this is a process as opposed to craft, which is product-orientated. Markowitz (1994) explained that art is often accorded higher status than craft. Understandings of blurred boundaries (Wallace, 2016) and creative blending (Knobel \& Lankshear, 2008) may be helpful in considering art and craft together rather than making a sharp distinction between them (Steele, 2009). For the purposes of this study, art and craft are conceived of as in a whole or continuum. Both forms of expression are used for creative communication and as prompts for generating visual data that can be analysed by means of interpretive engagement (Drew \& Guillemin, 2014). The Crafting Connections activity and accompanying freewriting may tend toward a craft positioning, while the visual results of the photo elicitation and collage processes may tend toward an art positioning in a gamut of creative expression. Creative activities offer something beyond the written text (Barone \& Eisner, 2011; Cahnmann-Taylor, 2017). Arts-based research "is uniquely suited to draw complex attention to an issue" (CahnmannTaylor, 2017, p. 249).

\section{Conceptual Lenses: Visual Activism and a Transformative Activist Stance}

Visual work has the potential to arrest attention and provoke thinking and action. Mitchell (2008) indicated that visual inquiry approaches are a powerful means of fostering reflexivity and, conceivably, of bringing about change. Art has been used for decades as a means of protest and way of advocating for particular issues (Chalabi, 2016; Morrow, 2007). Visual activism, or protesting through and with art, can include a rebellious element that stirs and percolates solidarity (Demos, 2016). Challenging authority or the status quo is possible with creative activism and an artfully designed aesthetic missive (Morrow, 2007). Moving from visual arts to the arena of psychology, Stetsenko (2011) uttered a strident call for action. Taking up a transformative activist stance provides a means of collaboratively altering present circumstances (Stetsenko, 2013). Bringing about change is essentially a creative process (Stetsenko, 2019), and we are assured that:

The core of creativity, like freedom, is about dissent, resistance, discord, challenge, critique, and ultimately, about acts of moving beyond what is given, a process that transcends (or deconstructs) the status quo and its entrenched structures, phenomena, and elements. (p. 2)

Importantly, the myth that only certain special individuals are endowed with creative propensity is dispelled - the seemingly ordinary and everyday action and interaction are indeed unique (Stetsenko, 2019) yet,

no human action is possible without a degree of creativity, innovation, authorship, and ingenuity, even when solving what appears to be everyday problems and common tasks in ordinary life, because no everyday task is ever completely common and no life is ever completely ordinary. (Stetsenko, 2018, p. 42)

Given the possibility that creative work can emerge from the ordinary and every day, attention now shifts to the methodological decisions that were taken in order to elicit data from our OBL team and critical friends. The data were envisaged as accounts of our usual and routine practices and the perceptions and intuitions linked to our practices. 


\section{Methodological positioning}

As the OBL team, we were keen to make sense of our student support activities and the insights of colleagues and thus worked from an interpretive perspective (Krauss, 2005). A creatively orientated practitioner inquiry seemed to be a useful way to look with new eyes at our student support initiatives and understandings. A common practice in practitioner-orientated research is the use of multiple methods (Mena \& Russell, 2017) and the triangulation of data elicited from several sources (Hamilton, 2013). Our improvement-focused inquiry included a range of methods (LaBoskey, 2004). An exhibition of artefacts, images, and documents was used to set the scene for the reflection on practice (see Images 2 and 3).

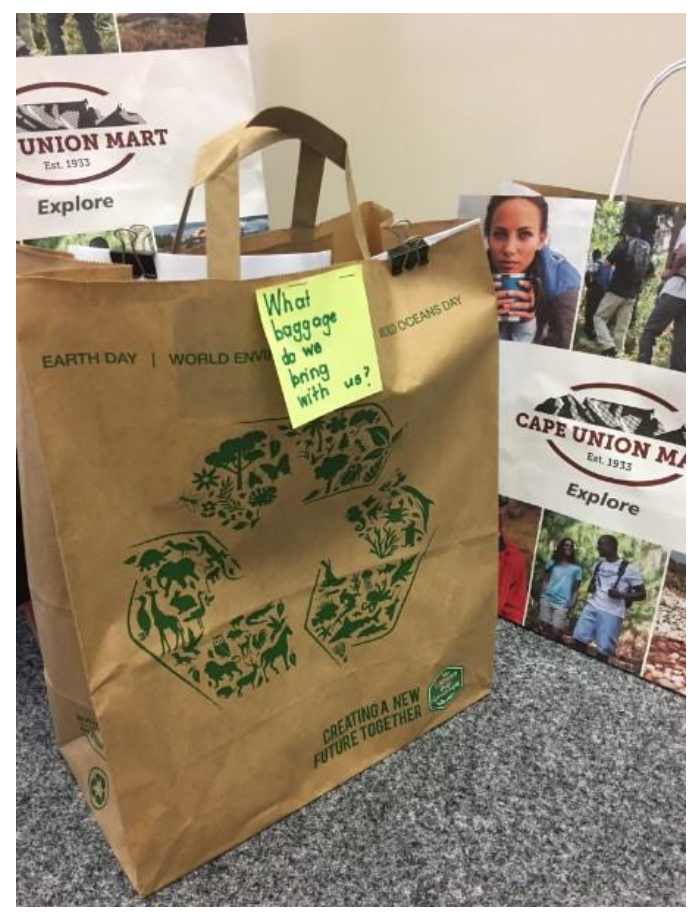

Image 2: An Exhibition of Artefacts: Paper Bag Artefacts to Prompt Reflection

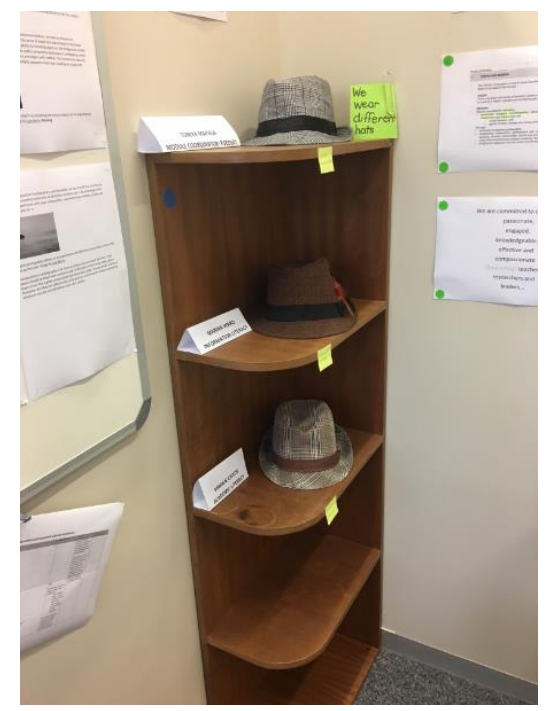

Image 3: An Exhibition of Artefacts: Displaying the Hats We Wore 
In addition, it was an opportunity to present our work for others to study and scrutinise (Hamilton \& Pinnegar, 1998). Photo elicitation, craftwork, and collage work followed the exhibition process so that creative activities could produce layers of meaning that might crystallise understanding.

In our engagement with first-year education students, we took on the roles of providing epistemological access, supporting acquisition of academic literacies, and training students in information literacy skills. Our different roles were characterised as hats we wore (Image 3 ). These roles coalesced as students were assisted with preparing a major assignment for the education module. In order to look critically at our work of integrating academic and information literacies into the content and assessment of a module, it was important to find colleagues similarly placed in the faculty of education and in library and information services because they would have substantial contextual understanding (Kosnik et al., 2006). Purposive sampling was envisaged in order to select colleagues willing to act as critical friends. Each team member was tasked with inviting two staff members. Colleagues with experience in presenting education modules and language work, and two trainers from the library tasked with supporting engagement with information literacy practices, were identified as well-placed to participate in the study. Ethics permission was sought and granted.

Ultimately, five colleagues, three from the faculty and two from the library, agreed to participate. These colleagues were invited to choose pseudonyms to position themselves in the study. Self-naming proved to be a significant aspect of the inquiry. As Allen and Wiles posited: "The care and thought with which many participants chose their names, and the meanings or links associated with those names, illuminated the importance of the process of naming" (2016, p. 149). Each critical friend had the opportunity to choose and explain the significance of their name as part of their contribution; selfnaming, as opposed to the imposition of pseudonyms, appeared to be valued by participants. "Lizzy" and "Phoeb" chose new names they enjoyed, while "Nta" and "Annie" chose derivatives of their own names. "Nesty" chose a name that closely represented the structure she wanted to craft.

Another means of allowing the self-positioning of participants was asking them to take photographs of their own craftwork as a record of the construction produced by each participant. The ubiquitous use of camera phones to document personal experience appears to be a hallmark of our times; personal photography use has evolved as a result of digital technologies (Van House, 2011). This form of visual communication has been described as "multiple, overlapping technologies: of memory; relationships; self-representation; and self-expression, all of which are changing in the digital environment" (Van House, 2011, p. 125).

Data, both visual and written, generated by critical friends and OBL team members is considered in this paper. Critical friends participated in a tactile-based craftwork activity (Groth et al., 2013) with accompanying freewriting (Elbow, 1998). OBL team members undertook various activities to explore their practice. The photo elicitation (Harper, 2002) and collective collage work (Pithouse-Morgan et al., 2016) of team members form the focus of this paper. In the next section, the creative contribution of critical friends will be considered first, and then the aesthetic reflections and representations of OBL team members will be represented.

\section{Insights of Critical Friends}

Inspired by experience of construction activities in early learning settings and their potential for collaborative learning, our team investigated areas of haptic perception and embodied knowing (Gulliksen, 2017). Understandings of making and learning from the process led to the development of Crafting Connections. This tactile, visible thinking strategy seemed to have the potential to assist participants to think collectively (Ritchhart \& Perkins, 2008). Our purposively selected colleagues were willing to participate in our hands-on data generation strategy. 
Craft, as a way of thinking while using material, can support scholarly undertakings (Nimkulrat, 2012). Embodied understanding is a significant aspect of craftwork (Koskinen et al., 2015). A thinking strategy such as Crafting Connections offers participants the opportunity to think with their hands (Groth, 2017) while manipulating and constructing with materials such as play dough, sucker sticks, pipe cleaners, and glass pebbles. The following prompt was provided to participants:

This activity encourages thinking with your hands.

Experimenting and sharing your thoughts as you go along is encouraged.

Use the materials in front of you to show your thinking:

- We will be considering how we can promote first-year student success.

- This is a broad topic. Think about an aspect of the topic you would like to portray.

Frame your response bearing the teaching and learning policy of the university in mind.

Write a brief accompanying text to assist viewers to interpret your work.

Share your work with other crafters.

An A3 laminated white board was used as a workspace for each crafter. The five participants created models in response to the prompt. After the construction phase, there was an opportunity for participants to provide a clarifying text. Freewriting offered an opportunity for participants to communicate their ideas without stopping to edit and correct (Elbow, 1998). This writing opportunity allowed crafters to offer an interpretation of their own work given that the visual and written texts may offer a harmonised message, may expand understanding, or may have a dissonance (Springgay et al., 2005). At the start of the activity, participants were asked to frame their work as mindful of the institutional teaching and learning policy. This was not to limit responses, but to add texture to the fabric of understanding in the institution regarding student support. Participants had the opportunity to craft in resonance with a vision of engagement with students articulated broadly as including a humanising pedagogical orientation informed by the institutional values of respect for diversity, excellence, ubuntu, integrity, and respect for the natural environment (Nelson Mandela University, 2019). Once participants had finished their crafted work, they were invited to freewrite about the piece that they had constructed (Image 4).

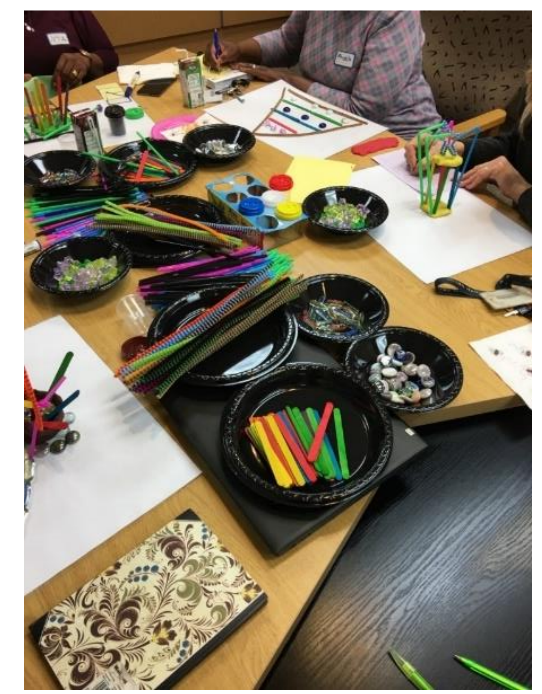




\title{
Image 4: Freewriting Informed by Crafting
}

There was an opportunity for each participant to share their work with the group. This communication offered the opportunity to find connections in a web of meaning making linked to the idea of promoting student success. After listening to all the presentations, participants were invited to formulate a phrase to sum up the message of their work. Participants were able to assert some control over the varied meanings emerging from their work (Levy, 2009). Importantly, as the researchers, we did not assume sole responsibility for analysing and determining the meaning of the participants' work. We were informed by the crafters' understandings as expressed in their construction and accompanying text.

At the close of the session, we asked participants to take photographs of their construction. They had the freedom to decide how to represent their work in a photograph. The affordances of photography such as positioning, framing, and other composition techniques could be considered by our participants when capturing an image and conveying a visual message about their work (Peterson, 2015).

After the collaborative session, work was returned to participants via email. Each participant received a photograph of their construction with the title and accompanying text. This format echoed a display at an art gallery with image, caption, and curatorial statement (Reinikainen \& Dahlqvist, 2016). Participants had the opportunity to revise the written text if need be. Two key areas emerged from the Crafting Connections insights of our colleagues. The first dealt with the "how" of student support and the second with the "what" of student support.

Both Annie and Nta emphasised that student support was important. Annie stressed that assistance and guidance were necessary while Nta emphasised the nurturing environment within which this should take place:

\begin{abstract}
Annie: Students need significant support and guidance to help them to become successful and reach their goals.

Nta: Creating a conducive environment to nurture all needs is vital. My craft represents the Garden of Hope. If it is taken care of, and well nurtured, it will grow beautiful flowers. Our students come from different backgrounds and different home environments. If they are shown empathy, respect, care, and treated with dignity and given hope, they are likely to grow into beautiful human beings.
\end{abstract}

Lizzy, Nesty, and Phoeb clarified what could be done to provide intentional, careful, and care-filled support. Lizzy drew attention to the agency of students as knowers. She disrupted the notion of staff being responsible for facilitating all learning. Nesty showed that recognising and appreciating students is vital and is a way of enactioning care and expediting learning. Phoeb presented an intricate design of student support. She held the view that learning could be facilitated through the connecting apparatus of staff and student interaction:

Lizzy: Aha moments are connecting moments. ... Students and teachers can learn from one another. 
Nesty: Student recognition and acknowledgement is key to facilitating student learning . . . it is necessary to have the attributes of care and support for learners to be sold on what you teach them.

Phoeb: Sharing mechanisms are the key to the success of learners. My craft represents knowledge creation from a learner's perspective.

The first line is in green representing basic needs that a learner has, according to Maslow.

In this pyramid, it shows starting to lecture the learner from what she or he knows.

White dots represent the scattered facts the learner has.

Blue dots are the combination of two colours - that literally reflect the combination of the lecturer's information and what the learner has.

This becomes knowledge that is reflected by the diamond, which is the combination of learner's raw facts and the lecturer's information.

Knowledge sharing mechanisms are the key to the success of the learners.

Simple but profound understandings emerged from the work of our critical friends. Accessing and managing knowledge in more innovative ways is vital (Ward, 2006). It seems that "a sense of knowing through making" (Groth, 2017, p. 14) was possible. Key understandings of student support are discernible as a result of critical friends using embodied knowledge (Groth, 2016).

A distinguished scholar of student support, Vincent Tinto, visited South Africa at the request of the Council on Higher Education (Tinto, 2014). Decades of work internationally (Tinto, 2012) assisted Tinto in developing three lessons related to student support in higher education (Tinto, 2014). There are interesting resonances between these lessons and the meaning making of the critical friends group:

First lesson: Providing students access without support is not opportunity. ... It is my view that once an institution admits a student, it becomes obligated to provide, as best it can, the support needed to translate the opportunity access provides, to success. (Tinto, 2014, p. 6)

All the responses confirmed a need for focused support. A range of assistance was envisaged by critical friends - staff members of a faculty or of library information services. In addition to academic support, social, emotional, and psychological support were valued as key areas of assistance for students (Palmer et al., 2011). Responses by Lizzy and Phoeb had an academic and social orientation to student support. Nta's response alluded to the need for emotional support, while the responses of Annie and Nesty referred to the importance of psychological support:

Second lesson: The classroom experience is central to student success... however we think about the strategies of promoting success, our efforts must begin, but not end, with students' classroom experiences. (Tinto, 2014, p. 6)

The classroom, or library training room, was seen as a place where direction is provided (Annie). It is also a space of acceptance where who you are and what you bring are welcomed (Lizzy, Nesty, Nta, and Phoeb). The institutional teaching and learning policy seemed well represented in these understandings of learning places and spaces. There was clear resonance with a humanising approach (del Carmen Salazar, 2013): 
The third and final lesson: Improvement in institutional rates of student success does not arise by chance. ... It requires an intentional, structured and coherent set of policies and actions that coordinate the work of many programmes and people across campus; actions that are sustained and scaled up over time and to which resources are allocated. There is no magic cure to improvement. It simply takes time and sustained effort. (Tinto, 2014, $p$. 6)

The imperative to take action was emphasised in the third lesson. Student support action was envisaged as guided (Annie), building on (Phoeb), connecting with (Lizzie), and valuing (Nesty) the treasures that students bring (del Carmen Salazar, 2013). These gifts students bring are to be nurtured in a conducive space so that all students can grow (Nta). The garden of hope envisaged by Nta fosters humanising by "catering for diversity and common growth in changing contexts" (Zinn et al., 2016, p. 90). So, the classroom, like a healthy garden, is not static. Growth and change are key properties of classrooms where student success is promoted.

\section{Insights of OBL Team Members}

We used photo elicitation as a tool to view and reflect on our practice and thinking about our own work and that of the team. Photographs are a powerful visual medium (Rose, 2013). Carefully selected, photographs may provide for research participants "a distance from what they are usually immersed in" (Rose, 2013, p. 28). Relative detachment can thus be used as a tool in the examination of practice. The unique properties of photographs were a key means of prompting collective reflection and introspection by us as OBL team members. We agreed with Rydzik et al. that "visuals can provide deep and multilayered understandings of the phenomena under examination and can offer a creative way to construct knowledge" (2013, p. 284). We set ourselves the task of each eliciting three photographs that expressed an aspect of our role in the OBL project. The online repository, Pexels (https://www.pexels.com/), was used as a source of copyright-free images. We wrote an accompanying text for each photograph. In order to facilitate collaboration and ongoing communication, the images and text were shared via email. The conversations we shared electronically helped us refine the choice of photographs, and sharpen thinking about the accompanying texts. Our engagement was both creative and critical, leading to heightened awareness and reflexivity (Palaganas et al., 2017). Evocative photographs chosen by team members served as a creative tool to prompt memory, reflection, and critique (Warren, 2002). The insights of our education specialist were captured in the notions of inclusive and collaborative learning environments (see Image 5). Diverse groups of students were helped to engage with unfamiliar content. The underpinning valuing of all participants was a key aspiration of this visual piece. This was expressed as "Umntu ngumntu ngabantu," emphasising the connecting bond of humanity: "I am because we are." 


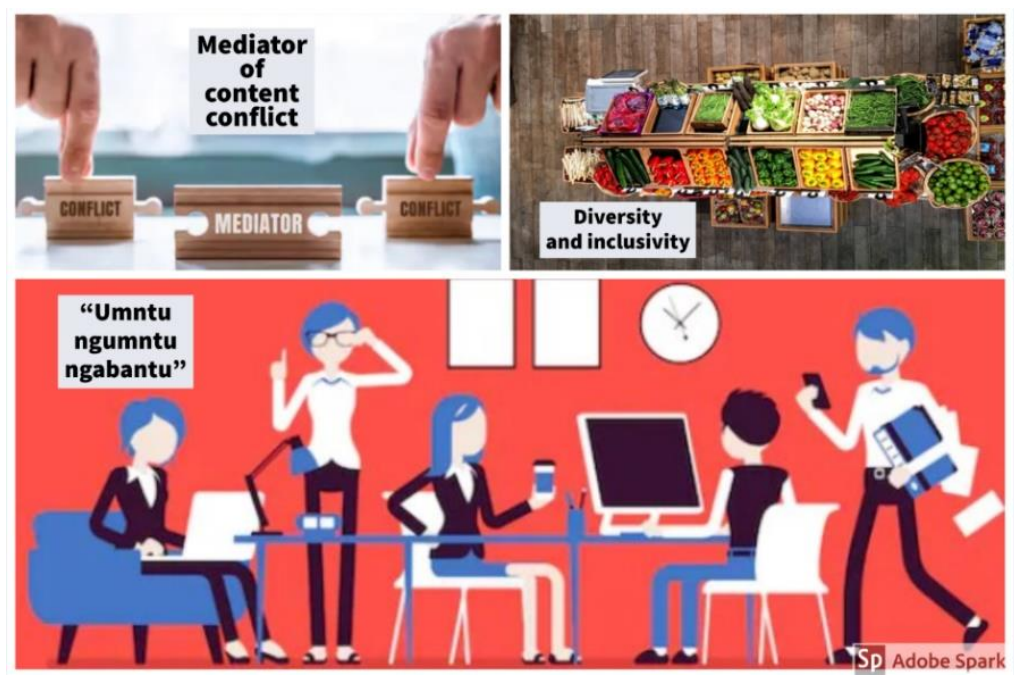

Image 5: Creation of Inclusive and Collaborative Learning Spaces

Image 6 , created by the academic literacies practitioner, surfaced a reminder of the importance of synergy in student support activities. In order to facilitate epistemological access, the collective efforts of staff members are necessary. The image boldly asserts that cohesive and interlinking support initiatives are vital.

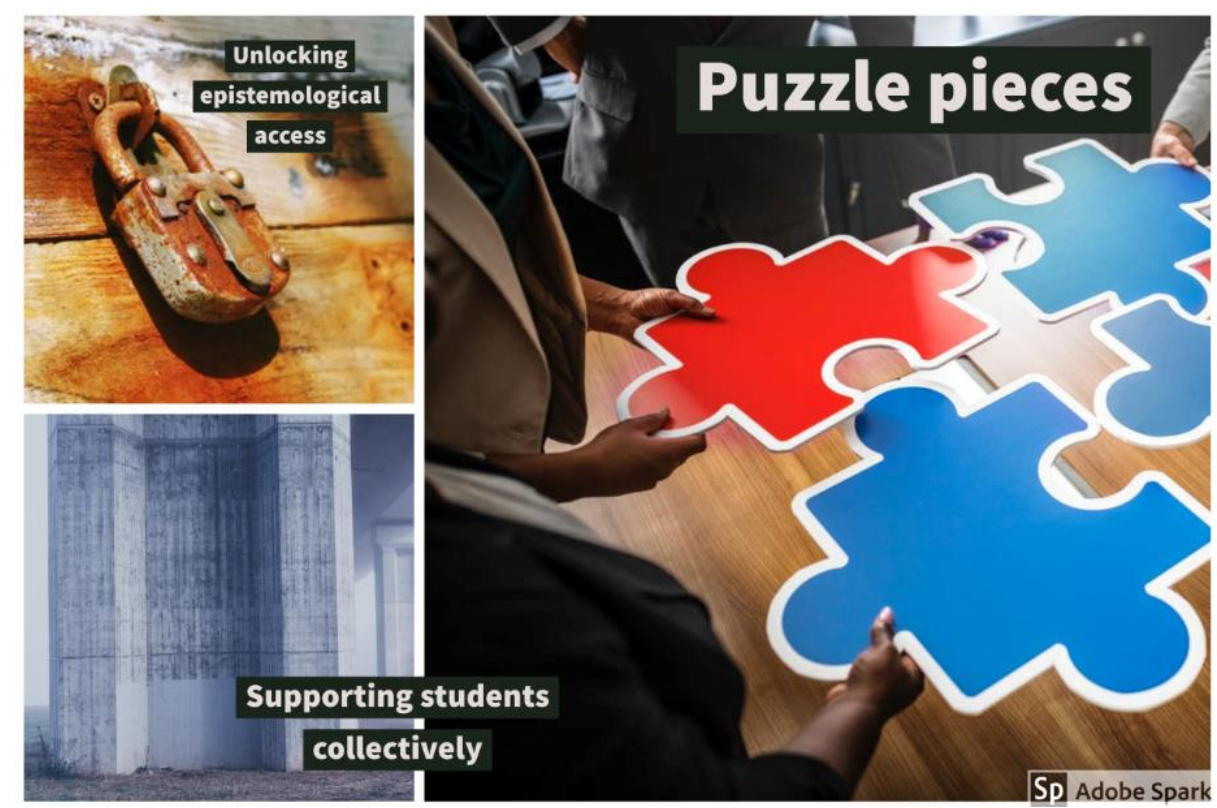

\section{Image 6: Collective Student Support}

The image produced by the teaching, learning, and research support librarian (Image 7) depicts how students should be assisted to navigate the sometimes overwhelming whirlpool of information. The collaborative support of staff sheds light in dark and uncertain spaces and helps students climb towards their goals. 


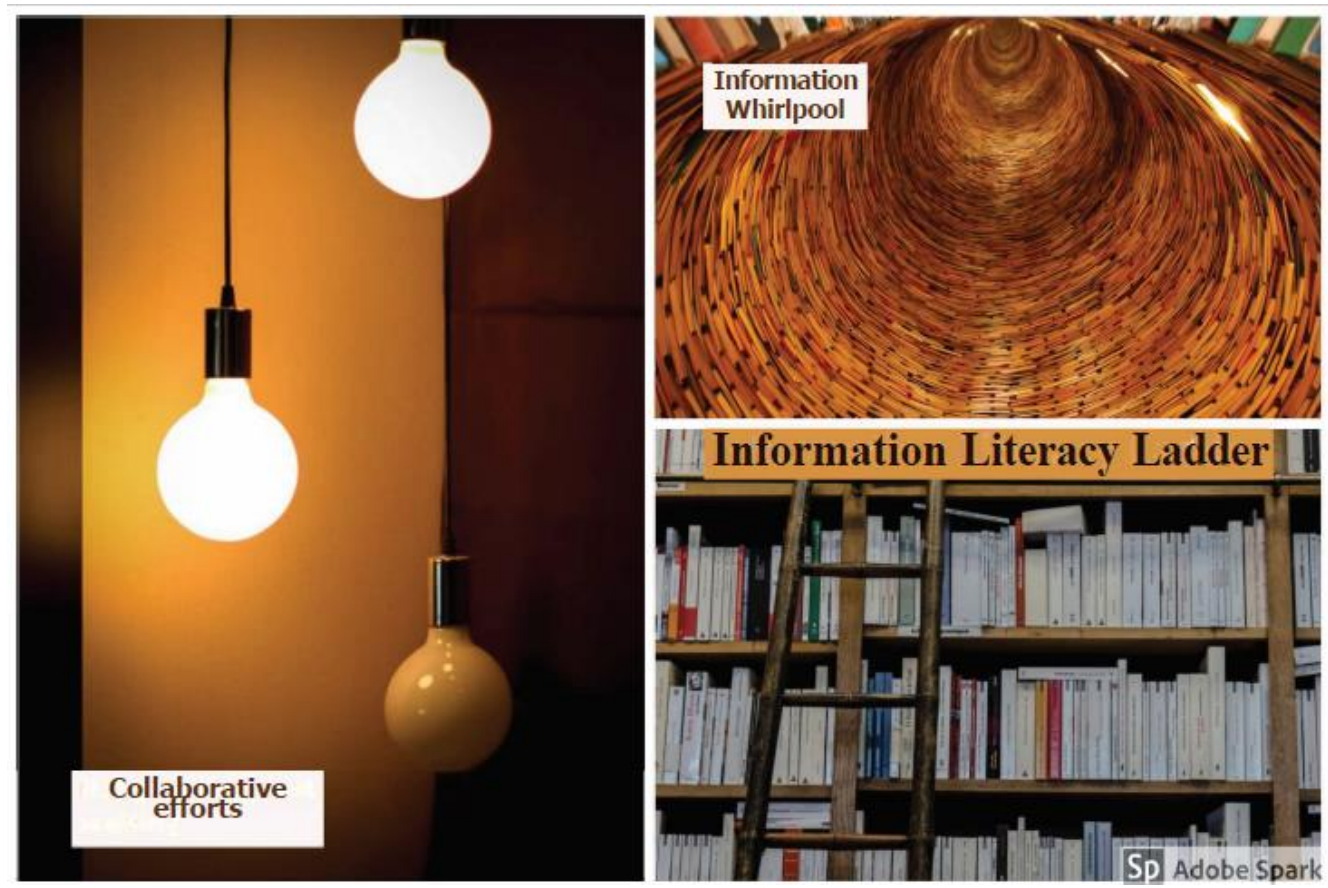

Image 7: Finding Your Way in the Maze of Information

We realised that it was important to interpret the collection of images and text systematically. The visual thinking strategy, Connect, Extend, Challenge (CEC) was chosen as a guidepost (Ritchhart \& Perkins, 2008). We displayed the photographs and clarifying texts in order to make our thinking explicit and to develop enhanced understanding (Ritchhart et al., 2011). We worked collectively to annotate with sticky tags in response to the following prompts:

- How are the ideas and information presented connected to what you know? (Connect)

- What new ideas extended or pushed your thinking in new directions? (Extend)

- What is still challenging or confusing for you? What questions, wonderings, or puzzles do you have? (Challenge) (Ritchhart \& Perkins, 2008).

As a follow-up process, the sticky tags were clustered and transcribed to extract key insights. Fifteen focus areas emerged. There was an opportunity for team members to check, amend, or augment the CEC interpretations and proposed focus areas. In order to achieve a sharper sense of practice, the focus areas were distilled and summarised. The focus areas were then arranged and grouped and four summary statements were prepared (Image 8). These statements helped the team connect with their practice and consider a way forward. 


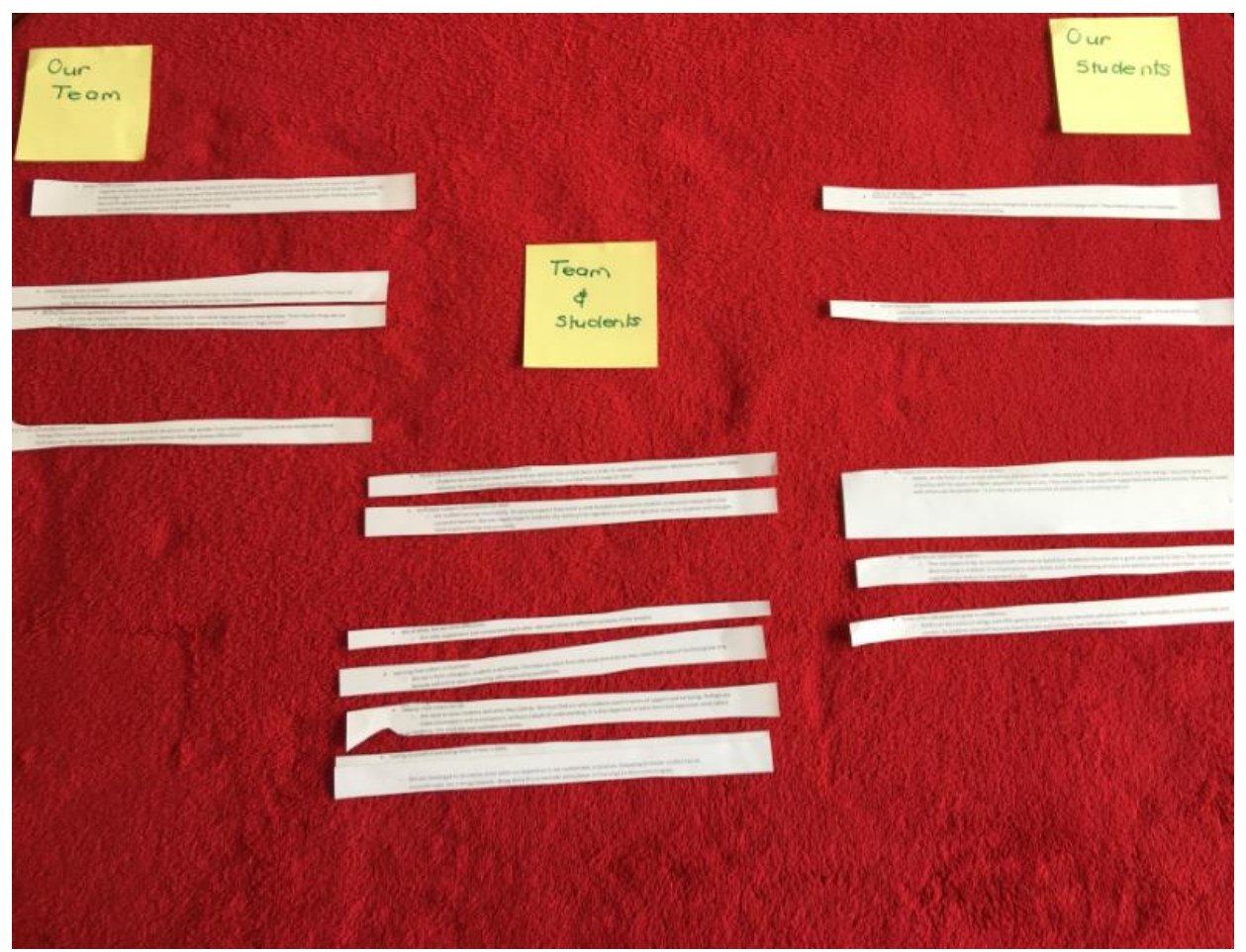

Image 8: Surfacing Summary Statements

\section{Summary Statement 1: Our Team}

Operating as a team has advantages - together we can do more! We are challenged to move from complacency to extend our work and find new ways to do things. Both our teaching and research need to be interrogated and questioned regularly and rigorously.

\section{Summary Statement 2: Our Team and Students}

Our way of mediating learning and offering scaffolded support has resulted in some student success. We have to remember the diverse range of students' backgrounds and knowledges. We can and must learn from what our students bring.

\section{Summary Statement 3: Our Team and Students}

Our contribution to student success is not uncomplicated-we shine differently. At times, we feel like a dimly lit bulb. It is OK to feel discomfort and some despondency. Our grappling and the grappling of our students brings rewards-prompting us (staff and students) to shine brighter. Others often help us move forward and shine more brightly.

\section{Summary Statement 4: Students}

Social learning holds much promise. Libraries are great social places to question, communicate, and learn. Books can be a place of refuge and provide a safe habitat and habitus to grow in confidence. Apples, the fruits of learning at the university, are yours to take and eat. They belong to you. Sharing apples (of learning) with others can be beneficial-it is a way of joining a community of practice as a university learner.

We also wanted to consider the insights of colleagues that had emerged from the Crafting Connections activity, together with the summary statements that had surfaced. Collage work seemed an ideal 
means of gluing together fragments of learning produced by critical friends and OBL team members. Image 9 depicts emerging understandings of the task of creating a welcoming space for students and staff to thrive and share the gifts of learning. Holbrook and Pourchier (2014) offered a thoughtprovoking view of collage as a means of analysis in a research study: "Art-making within inquiry becomes a rigorous articulation process through which sense (rather than meaning) is tentatively fabricated" (p. 754). Instead of the concepts of collecting, analysing, and making meaning, we are challenged to consider hoarding, mustering, and folding/unfolding/refolding as means of sharing the fruits of an inquiry process (Holbrook \& Pourchier, 2014). Collage can be used to negotiate meaning (Butler-Kisber, 2008). This mediation takes place between the creator of the collage and the viewer. Understood in this way, collage can become an important tool in a repertoire of communication about practice. We thought that the collage artefact could be used to disseminate our understandings of student support and the improvement of our practice in our university and further afield. We realised that the collage could also be used as a stimulus for conversations with students about their needs (Jahn, 2018). The purpose of collage as a means of sense making, according to Holbrook and Pourchier (2014), is "not to conclude with answers but to pause, gather energy, and invite comments until questions spur them on again" (p. 754). The lack of finality, and the imperative to continue pondering and questioning seemed to resonate well with our intention to regularly interrogate our practice and seek improved ways to offer student support.

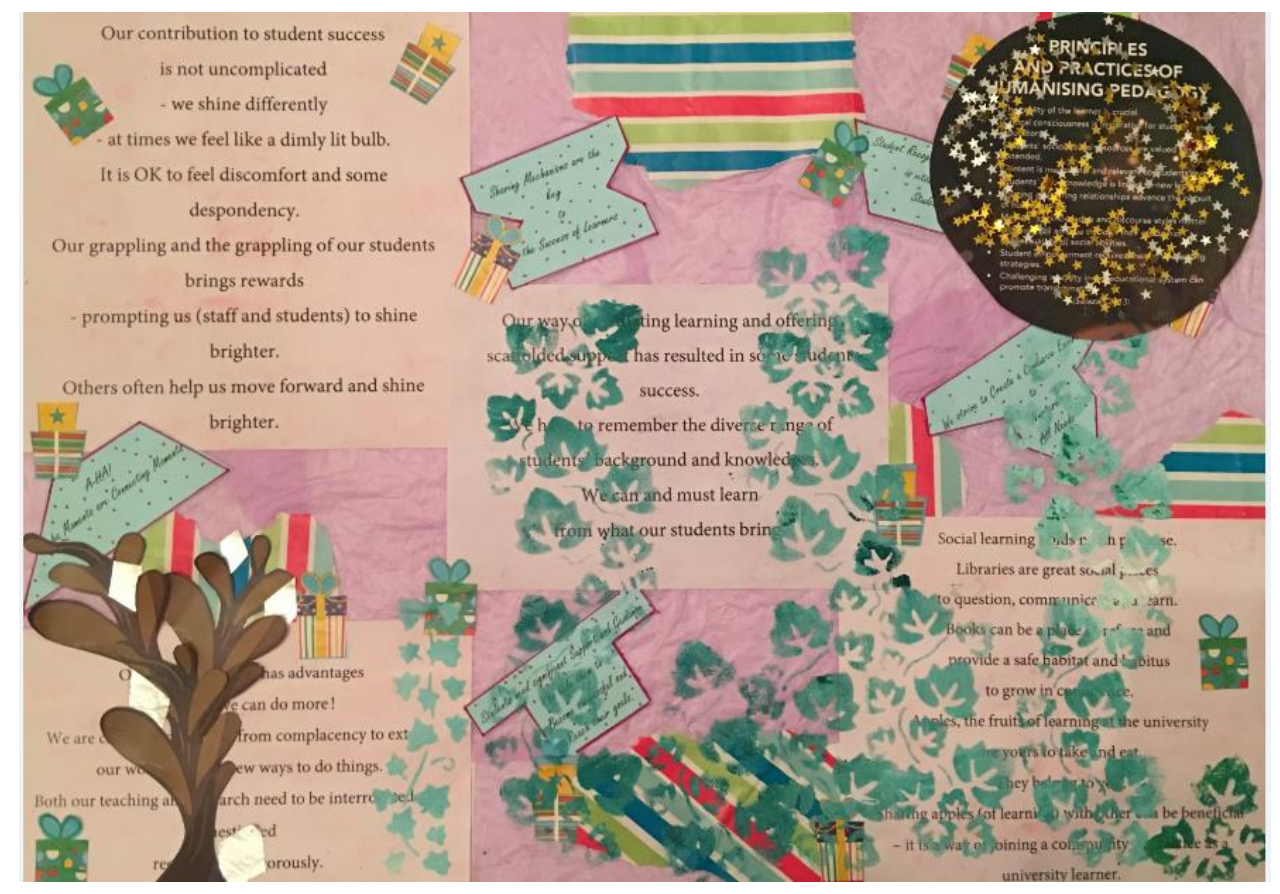

Image 9: Collaging a Space of and for Gifts of Learning

The garden-themed collage that we created collectively was intended as a cooperative and aesthetic process. Aspects such as colour, shape, and composition were key considerations for us during the collage making process (Fogarty et al., 2001). Juxtaposition of elements arising from the Crafting Connections activity and photo elicitation process was an important factor during the collage work (Morgaine, 2018). It was a means for us to bring together ideas of colleagues and team members in order to discern areas of similarity and dissonance and to make sense of student support in a changing higher education environment. In our collage, a humanising approach shines and sparkles-bringing warmth to the learning space where the gifts students and staff bring are appreciated and valued. 


\section{Discerning Seeds of Aesthetic Activism}

South African artist, Zanele Muholi, is acknowledged as having developed the concept of visual activism (Bryan-Wilson et al., 2016). This means of aesthetic activism is a way of positioning self (Muholi, 2012) and is "meant to focus attention ... to disrupt business as usual, if only briefly, or even, possibly, to effect change" (Bryan-Wilson et al., 2016, p. 6). Carefully crafted images and representations can be used to disrupt the usual and the taken-for-granted.

Through creative activism, reconceptualisation and rethinking are possible (Morrow, 2007). The collage sense-making activity we undertook gave rise to an artefact that captures the wisdom of the participants. The viewer is presented with a depiction of a space that welcomes the gifts that students and staff bring (del Carmen Salazar, 2013). The nurturing garden of hope (Nta) is an enabling environment (Nesty) where students and staff are equal (Lizzie) and valued as carefully wrapped presents. Mutual respect and collaboration (Annie) produce a healthy, balanced ecosystem. Nestled among the foliage are diamonds created by the interaction of learners' raw facts and the lecturers' information (Phoeb).

We realised that the summary statements can be read against and with the collage in order to surface ideas on how to take our practice forward. This could instigate a shift in the OBL team to find new ways to do things as a result of interrogated and questioned facilitation of learning and scholarly practice (Statement 1). A refrain of intentional discomfort echoes with calls to leave complacency (Statement 1), destruct the status quo, and eschew usual practice (Bryan-Wilson et al., 2016; Stetsenko, 2019). Although efforts to support students were fairly successful, resulting in some student success (Statement 2), many students struggle to meet the requirements of the major education module and other first-year modules. This suggested to us that the university and faculty have to rethink the support structures and procedures in place, and consider alternative avenues of assistance.

Another necessary shift is that of acknowledging that staff can learn from students (Statement 2). This disrupts the notion of staff as all knowing and students as empty vessels that need to be filled (Freire, 1996). Students have diverse experience and knowledges (Statement 2) that can and should be recognised. Phoeb presented an intricate linking of Maslow's hierarchy of needs (Maslow, 2013) and the data-information-knowledge-wisdom (DIKW) hierarchy (Rowley, 2007). The learners' raw facts are combined with the lecturers' information (Phoeb). The interaction between student and lecturer is signified as a sharing one that disturbs traditional power relations in academic settings. Both students and staff struggle towards success. This grappling brings rewards, although it might result in despair at times (Statement 3).

The collective struggle, the action of combining data and information to form knowledge and perhaps wisdom (Rowley, 2007), holds much promise (Statement 4). There is a call to action-apples, the fruits of learning at the university, are yours to take and eat (Statement 4). Knowledge steeped in sociocultural contexts can be grasped "through interrogation and active exploration by learners" (Vianna \& Stetsenko, 2017, p. 252). Importantly, students are seen as having agency. They are envisaged as having agentive creativity (Stetsenko, 2018), and not as the passive recipients of student support. 


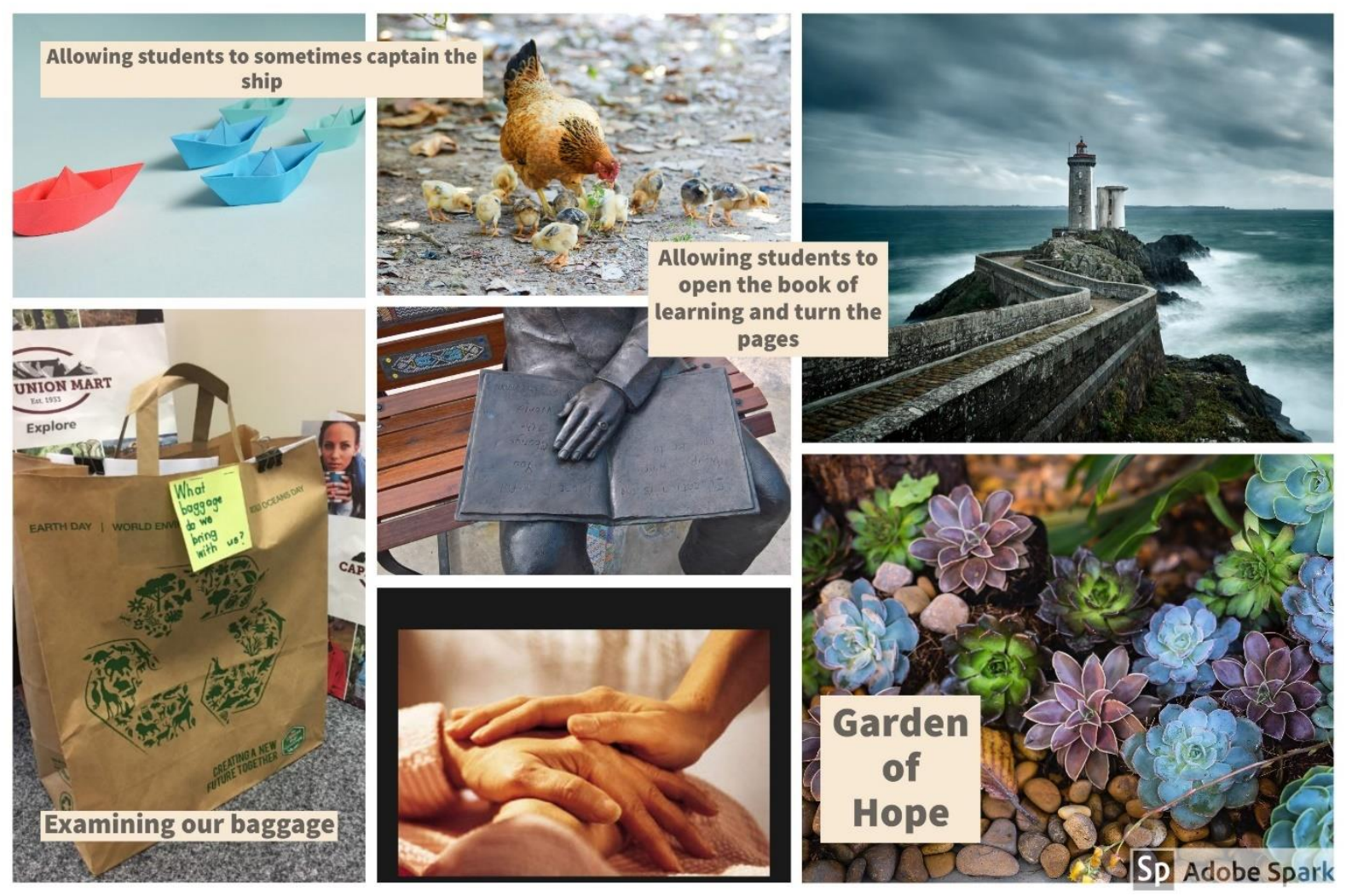

\section{Image 10: Confronting Baggage Brought to a Garden of Hope}

As a team, we had to acknowledge and examine the baggage we carried along with us. The roles we assumed sometimes cast students in deficit ways. During our reflections, metaphors surfaced at different stages. Two key ideas came to the fore. The first related to care and the second to navigating a difficult space. We described ourselves in ways that showed our care with tags such as "Caring supervisor," providing a comforting touch and "Mother hen," looking after chicks. Both these metaphors resonated with the care academics should show towards first-year students. The "Captain of a ship" and "Beacon guiding to a safe harbour" echoed the guidance staff are required to provide. However, at a point, students are no longer novices. They gain skills and awarenesses that allow them to proceed independently. A hard reality confronted us. There were times that we, instead of the students, opened the book of learning and turned the pages. If we were sincere about the idea of a garden of hope, we had to allow students to become independent and self-sufficient. Although we may have created the garden, the students themselves had to take root. The ecosystem of the garden had to become balanced, with transformative learning (Lange, 2012) as key feature. Over helping would be as damaging as over watering a garden. We realised, in going forward, that we had to have the courage to allow students to make their own way, to grow towards the light, unencumbered by ties and supporting stakes. We had to learn to grow with and not grow for our students.

\section{Conclusion}

The craft- and arts-based procedures used by our team and critical friends surfaced important messages and prompts for action. These creative affordances helped colleagues from the faculty of education and from library and information services to think in fresh ways about institutional and own visions of student support. The image of a garden of hope coalesced understandings and the sense making of participants. This verdant metaphor captured the insights of staff, and showed us how students can be provided with a safe place and nurturing environment to grow towards their goals and aspirations. Allowing students the space to grow and take responsibility is essential. Balancing nurturing with respect for agency is a key task in the student support process. 
Craft- and arts-based activities allow practitioners to venture beyond the taken-for-granted. Creative procedures provide an opportunity for introspection and meaning making and may prompt the transformation of practice. Our innovative contribution, Crafting Connections, offers practitioners a way to think with their hands and, possibly, discover the unexpected. Transformation of self and practice is essentially a creative process of slipping beyond entrenched habits of mind and established structures to discover new habitats of practice and ways of being.

\section{References}

Allen, R. E., \& Wiles, J. L. (2016). A rose by any other name: Participants choosing research pseudonyms. Qualitative Research in Psychology, 13(2), 149-165.

Barone, T., \& Eisner, E. W. (2011). Arts based research. SAGE.

Berry, M., \& Russell, T. (2014). Critical friends, collaborators and community in self-study. Studying Teacher Education, 10(3), 195-196. DOI: 10.1080/17425964.2014.958283

Bryan-Wilson, J., González, J., \& Willsdon, D. (2016). Editors' introduction: Themed issue on visual activism. Journal of Visual Culture, 15(1), 5-23

Butler-Kisber, L. (2008). Collage as inquiry. In J. G. Knowles \& A. L. Cole (Eds.), Handbook of the arts in qualitative research (pp. 265-276). SAGE.

Butler-Kisber, L., \& Poldma, T. (2010). The power of visual approaches in qualitative inquiry: The use of collage making and concept mapping in experiential research. Journal of Research Practice, 6(2), M18-M18.

Cahnmann-Taylor, M. (2017). Four guiding principles for arts-based research practice. Arts-Based Research in Education: Foundations for Practice, 2, 247-258.

Chalabi, D. (2016). What is visual activism? Journal of Visual Culture, 15(1), 32-34.

del Carmen Salazar, M. (2013). A humanizing pedagogy: Reinventing the principles and practice of education as a journey toward liberation. Review of Research in Education, 37(1), 121-148.

Demos, T. (2016). Between rebel creativity and reification: For and against visual activism. Journal of Visual Culture, 15(1), 85-102.

Drew, S., \& Guillemin, M. (2014). From photographs to findings: Visual meaning-making and interpretive engagement in the analysis of participant-generated images. Visual Studies, 29(1), 5467.

Eisner, E. W. (1984). The art and craft of teaching. In J. Reinhartz (Ed.), Perspectives on effective teaching and the cooperative classroom (pp. 19-31). National Education Association USA.

Elbow, P. (1998). Writing with power: Techniques for mastering the writing process: Oxford University Press.

Fogarty, J., Forlizzi, J., \& Hudson, S. E. (2001). Aesthetic information collages: Generating decorative displays that contain information. In J. Marks \& E. D. Mynatt (Eds.), Proceedings of the 14th annual ACM symposium on user interface software and technology, Orlando, Florida.(141-150). https://doi.acm.org/10.1145/502348.502369

Freire, P. (1996). Pedagogy of the oppressed. (revised ed.). Continuum.

Groth, C. (2016). Design-and craft thinking analysed as embodied cognition. FormAkademisk:

Forskningstidsskrift for design og designdidaktikk, 9(1).

https://doi.org/10.7577/formakademisk.1481

Groth, C. (2017). Making sense through hands: Design and craft practice analysed as embodied cognition. Aalto University. 
Groth, C., Mäkelä, M., \& Seitamaa-Hakkarainen, P. (2013). Making sense. What can we learn from experts of tactile knowledge? FormAkademisk: Forskningstidsskrift for design og designdidaktikk, 6(2). https://doi.org/10.7577/formakademisk.656

Gulliksen, M. S. (2017). Making matters? Unpacking the role of practical aesthetic making activities in the general education through the theoretical lens of embodied learning. Cogent Education, 4(1), Article 1415108.

Hamilton, M. L. (2013). Using pictures at an exhibition to explore my teaching practices. In C. Mitchell, K. O’Reilly-Scanlon, \& S. Weber (Eds.), Just who do we think we are? (pp. 71-81). Routledge.

Hamilton, M. L., \& Pinnegar, S. (1998). Conclusion: The value and promise of self-study. In M. L. Hamilton (Ed.), Reconceptualizing teaching practice: Developing competence through self-study (pp. 235-246). Falmer.

Harper, D. (2002). Talking about pictures: A case for photo elicitation. Visual Studies, 17(1), 13-26.

Holbrook, T., \& Pourchier, N. M. (2014). Collage as analysis: Remixing in the crisis of doubt. Qualitative inquiry, 20(6), 754-763.

Jahn, S. A. (2018). Using collage to examine values in college career counseling. Journal of College Counseling, 21(2), 180-192.

Knobel, M., \& Lankshear, C. (2008). Remix: The art and craft of endless hybridization. Journal of Adolescent \& Adult Literacy, 52(1), 22-33.

Koskinen, A., Seitamaa-Hakkarainen, P., \& Hakkarainen, K. (2015). Interaction and embodiment in craft teaching. Techne serien: Forskning i Slöjdpedagogik och Slöjdvetenskap, 22(1), 59-72.

Kosnik, C., Beck, C., Freese, A. R., \& Samaras, A. P. (2006). Making a difference in teacher education through self-study: Studies of personal, professional and program renewal (Vol. 2). Springer.

Krauss, S. E. (2005). Research paradigms and meaning making: A primer. The Qualitative Report, 10(4), 758-770.

LaBoskey, V. K. (2004). The methodology of self-study and its theoretical underpinnings. In J. J. Loughran, M. L. Hamilton, V. Kubler-LaBosky, \& T. Russell (Eds.), International handbook of selfstudy of teaching and teacher education practices (pp. 817-869). Springer.

Lange, E. A. (2012). Is Freirean transformative learning the Trojan horse of globalization and enemy of sustainability education? A response to C. A. Bowers. Journal of Transformative Education, 10(1), $3-21$.

Levy, P. (2009). Method meets art: Arts-based research practice. Guilford Press.

Mannay, D. (2010). Making the familiar strange: Can visual research methods render the familiar setting more perceptible? Qualitative Research, 10(1), 91-111.

Markowitz, S. J. (1994). The distinction between art and craft. Journal of Aesthetic Education, 28(1), 55-70.

Masinga, L., Myende, P., Marais, A., Singh-Pillay, A., Kortjass, M., Chirikure, T., \& Mweli, P. (2016). "Hear our voices": A collective arts-based self-study of early-career academics on our learning and growth in a research-intensive university. Educational Research for Social Change, 5(2), 117-135.

Maslow, A. H. (2013). A theory of human motivation. Simon and Schuster.

McLennan, D. M. P. (2010). Process or product? The argument for aesthetic exploration in the early years. Early Childhood Education Journal, 38(2), 81-85. 
Mena, J., \& Russell, T. (2017). Collaboration, multiple methods, trustworthiness: Issues arising from the 2014 international conference on self-study of teacher education practices. Studying Teacher Education, 13(1), 105-122.

Mitchell, C. (2008). Getting the picture and changing the picture: Visual methodologies and educational research in South Africa. South African Journal of Education, 28(3), 365-383.

Mitchell, C., de Lange, N., \& Moletsane, R. (2017). Participatory visual methodologies: Social change, community and policy. SAGE.

Morgaine, K. (2018). Fragments/layers/juxtaposition: Collage as a data-analysis practice. In M. CapousDesyllas \& K. Morgaine (Eds.), Creating social change through creativity: Anti-oppressive arts-based research methodologies (pp. 227-241). Palgrave Macmillan.

Morrow, R. (2007). Creative activism: A pedagogical and research tool. Enquiry The ARCC Journal for Architectural Research, 4(1), 60-68. https://doi.org/10.17831/enq:arcc.v4i1.56

Muholi, Z. (2012). Faces and phases. Transition: An International Review, (107), 113-124.

Naumes, W., \& Naumes, M. J. (2014). The art and craft of case writing. Routledge.

Nelson Mandela University. (2019). Nelson Mandela University Library and Information Services Vision Statement. https://library.mandela.ac.za/Home/Mission-vision

Niedderer, K., \& Townsend, K. (2014). Designing craft research: Joining emotion and knowledge. The Design Journal, 17(4), 624-647

Nimkulrat, N. (2012). Hands-on intellect: Integrating craft practice into design research. International Journal of Design, 6(3), 1-14.

Palaganas, E. C., Sanchez, M. C., Molintas, V. P., \& Caricativo, R. D. (2017). Reflexivity in qualitative research: A journey of learning. Qualitative Report, 22(2), Article 5.

Palmer, R. T., Davis, R. J., \& Maramba, D. C. (2011). The impact of family support on the success of black men at an historically black university: Affirming the revision of Tinto's theory. Journal of College Student Development, 52(5), 577-597.

Peterson, B. (2015). Learning to see creatively: Design, color, and composition in photography. Amphoto Books.

Pithouse-Morgan, K., Coia, L., Taylor, M., \& Samaras, A. P. (2016). Exploring methodological inventiveness through collective artful self-study research. LEARNing Landscapes, 9(2), 443-460.

Reinikainen, L., \& Dahlqvist, H. Z. (2016). Curating an exhibition in a university setting. In D. Pillay, I. Naicker, \& K. Pithouse-Morgan (Eds.), Academic autoethnographies (pp. 69-83). Springer.

Ritchhart, R., Church, M., \& Morrison, K. (2011). Making thinking visible: How to promote engagement, understanding, and independence for all learners: John Wiley.

Ritchhart, R., \& Perkins, D. (2008). Making thinking visible. Educational Leadership, 65(5), 57-61.

Rolling Jr, J. H. (2010). A paradigm analysis of arts-based research and implications for education. Studies in Art Education, 51(2), 102-114.

Rose, G. (2013). On the relation between "visual research methods" and contemporary visual culture. The Sociological Review, 62(1), 24-46.

Rowley, J. (2007). The wisdom hierarchy: Representations of the DIKW hierarchy. Journal of Information Science, 33(2), 163-180.

Rydzik, A., Pritchard, A., Morgan, N., \& Sedgley, D. (2013). The potential of arts-based transformative research. Annals of Tourism Research, 40, 283-305. 
Samaras, A. P. (2010). Self-study teacher research: Improving your practice through collaborative inquiry. SAGE.

Springgay, S., Irwin, R. L., \& Kind, S. W. (2005). A/r/tography as living inquiry through art and text. Qualitative inquiry, 11(6), 897-912.

Steele, J. (2009). Tackling art/craft nomenclature, again, with particular reference to octogenarian potter Alice Qga Nongebeza, of Eastern Cape, South Africa. South African Journal of Art History, 24(1), 181-195.

Stetsenko, A. (2011). From relational ontology to transformative activist stance on development and learning: Expanding Vygotsky's (CHAT) project. In P. E. Jones (Ed.), Marxism and Education (pp. 165-192). Palgrave Macmillan.

Stetsenko, A. (2013). The challenge of individuality in cultural-historical activity theory: "Collectividual" dialectics from a transformative activist stance. Outlines: Critical Practice Studies, 14(2), 07-28.

Stetsenko, A. (2018). Agentive creativity in all of us: An egalitarian perspective from a transformative activist stance. In M. C. Connery, V. John-Steiner, \& A. Marjanovic-Shane (Eds.), Vygotsky and creativity: A cultural-historical approach to play, meaning making, and the arts (2nd ed., pp. 4160). Peter Lang.

Stetsenko, A. (2019). Creativity as dissent and resistance: Transformative approach premised on social justice agenda. In I. Lebuda \& V. P. Glăveanu (Eds.), The Palgrave handbook of social creativity research (pp. 431-445). Palgrave Macmillan.

Tinto, V. (2012). Enhancing student success: Taking the classroom success seriously. Student Success, $3(1), 1-8$.

Tinto, V. (2014). Tinto's South Africa lectures. Journal of Student Affairs in Africa, 2(2), 5-28.

Tishman, S., \& Palmer, P. (2005). Visible thinking. Leadership Compass, 2(4), 1-3.

Van House, N. A. (2011). Personal photography, digital technologies and the uses of the visual. Visual Studies, 26(2), 125-134.

Vianna, E., \& Stetsenko, A. (2017). Expanding student agency in the introductory psychology course: transformative activist stance and critical-theoretical pedagogy. In R. Obeid, A. Schartz, C. ShaneSimpson, \& P. J. Brooks (Eds.), How we teach now: The GSTA guide to student-centered teaching (pp. 252-269). Society for the Teaching of Psychology. http://teachpsych.org/ebooks/

Wallace, K. S. (2016). An exploratory study of learning journeys for makers in the fields of art, craft and design: An investigation of the blurred boundaries between art, craft, and design. [Unpublished master's thesis]. The Ohio State University.

Ward, D. (2006). Revisioning information literacy for lifelong meaning. The Journal of Academic Librarianship, 32(4), 396-402.

Warren, S. (2002). "Show me how it feels to work here": Using photography to research organizational aesthetics. Ephemera, 2(3), 224-245.

Weber, S. (2014). Arts-based self-study: Documenting the ripple effect. Perspectives in Education, $32(2), 8-20$.

Wildavsky, A. (2017). Speaking truth to power: Art and craft of policy analysis. Routledge.

Williams, B. (2002). Using collage art work as a common medium for communication in interprofessional workshops. Journal of Interprofessional Care, 16(1), 53-58.

Zinn, D., Adam, K., Kurup, R., \& du Plessis, A. (2016). Returning to the source: Reflexivity and transformation in understanding a humanising pedagogy. Educational Research for Social Change, 5(1), 70-93. 